\section{Military Technical College Kobry El-Kobbah, Cairo, Egypt.}

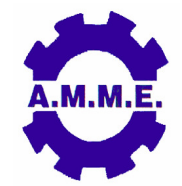

\title{
FINITE ELEMENT MODELLING OF DAMAGE FRACTURE AND FRETTING FATIGUE
}

\author{
M. Abdel Wahab*, I. Hilmy ${ }^{\star *}$, T. Hafiz ${ }^{* \star *}$ and R. Hojjati Talemi ${ }^{\star \star * *}$
}

\begin{abstract}
This paper summarises the research carried out to develop Finite Element (FE) modelling and predictive techniques for damage, fracture, fatigue and fretting fatigue problems. A damage model is developed based on Continuum Damage Mechanics and integrated within FE code. It is then used to predict the number of cycles to crack initiation in adhesively bonded joints. Furthermore, crack propagation algorithm is programmed within FE code using the principles of Fracture Mechanics and Paris law. The effect of mode mixity on crack propagation is taken into account using a Double Cantilever Beam (DCB) test specimen. Moreover, FE model of fretting fatigue aluminium test specimen is carried out in order to study the stress distribution and predict the crack propagation fatigue lifetime. Fretting fatigue problems involve two types of analyses; namely contact mechanics analysis and damage/fracture mechanics analysis. Both analyses are performed in FE code and the stress distribution along the contact surface between the two bodies is obtained and analysed. Furthermore, crack propagation analysis under fretting fatigue condition is presented. In most cases, the numerical results are compared to experimental ones.
\end{abstract}

\section{KEY WORDS}

FEA, Damage Mechanics, Fracture Mechanics, Fretting Fatigue, Crack Initiation, Crack Propagation.

\footnotetext{
* Professor, Dept. of Mech. Const. and Production, Ghent University, Belgium.

** Assistant professor, MME Dept, Faculty of Engineering, IIUM, Malaysia (email: ihilmy@iium.edu.my).

*** Graduated PhD student, Faculty of Eng. and Phys. Sci., University of Surrey, UK. ${ }^{* * * * G r a d u a t e}$ student, Dept. of Mech. Const. and Prod., Ghent University, Belgium.
} 


\section{NOMENCLATURE}

$\begin{array}{ll}A & \text { Damage parameter } \\ D & \text { Damage variable } \\ G_{l} & \text { Mode I strain energy release rate } \\ G_{\| I} & \text { Mode II strain energy release rate } \\ G_{C} & \text { Fracture toughness } \\ G_{t h} & \text { Fatigue threshold } \\ G_{\max } & \text { Maximum strain energy release rate } \\ K_{I} & \text { Mode I stress intensity factor } \\ K_{I I} & \text { Mode II stress intensity factor } \\ K_{I C} & \text { Mode I critical stress intensity factor } \\ N & \text { Number of cycles } \\ N_{f} & \text { Number of cycles to failure } \\ n, n_{1} \text { and } n_{2} & \text { Fatigue constants } \\ m & \text { Power constant in Ramberg-Osgood equation } \\ R_{V} & \text { Triaxiality function } \\ T_{x} & \text { Triaxiality ratio } \\ \Delta \sigma_{e q} & \text { Range of von Mises stress } \\ \Delta \sigma_{e q}^{*} & \text { Range of von Mises stress range for virgin material } \\ \beta & \text { Damage parameter } \\ \theta_{2} & \text { Crack propagation angle } \\ V & \text { Poisson's Ratio } \\ \sigma_{e q} & \text { von Mises equivalent stress } \\ \sigma_{H} & \text { Hydrostatic stress }\end{array}$

\section{INTRODUCTION}

The failure mechanism in adhesively boned joints may have different configurations according to joint geometry and loading conditions. Failure caused by fatigue loading is estimated as $50-90 \%$ of the total failure cases [1]. The total fatigue lifetime is in general divided into two main parts, namely crack initiation and crack propagation lifetimes.

In the literature, the phenomenon of fatigue crack growth has been understood to some extent, but the phenomenon of crack initiation has not yet been fully understood. However, there is still a disagreement among adhesive bonding scientists about which of these two phenomena contributions the most in joint lifetime. Different ratios of crack initiation to crack propagation lifetimes may be found depending on how crack initiation is measured and defined, and what techniques are used in order to monitor crack propagation [2]. Crocombe et al. [3] have found that for adhesive joints with fillet, more than $50 \%$ of the lifetime was dominated by crack initiation, while if the fillet was removed, joint lifetime significantly decreased and crack initiation lifetime was almost zero. They also found that the ratio of crack initiation lifetime to propagation lifetime increased as the level of load decreased. Harris and Fay [4] have found that fatigue lifetime in a single lap joint was dominated 
by crack initiation. Marcadon et al. [5] have found that the crack propagation of Tjoints dominated about two third of fatigue failure lifetime. Furthermore, Zhang et al. [6] have found that the ratio of crack initiation to crack propagation lifetimes of single lap joints was not constant.

Crack propagation lifetime may be analysed and predicted using the principle of fracture mechanics [7]. In adhesively bonded joints, due to the constraints applied by the substrates the crack usually grows either in the adhesive layer or along the adhesive/substrate interface. The crack growth is, therefore, very often due to shear loading (mode II) or tension and shear loading (mixed-mode) [8]. A considerable amount of research work has been carried out to characterise the crack propagation in adhesively bonded joints under pure mode I condition. However, even a simple configuration of adhesive joint shows a complex stress state at the interface leading to mixed mode crack propagation. Therefore, there is a need for mixed-mode crack propagation characterisation. Although, many papers have been published on the experimental measurement of mixed mode I/II fracture of adhesive joints and composite structures $[9,10]$, they do not cover the entire range of mode mixities from pure mode I to pure mode II.

Fretting fatigue is a phenomenon that takes place at the interface between two bodies in contact. One of these two bodies is subjected to oscillating loads and producing sliding movements at the contact surface. Due to fretting fatigue, many catastrophic failures of mechanical engineering components have been reported. This has been observed in many applications such as bolded or riveted joints [11], shrink-fitted shafts [12] and blade dovetail of turbo machinery [13]. The textbook 'Mechanics of Fretting Fatigue' by Hills and Novell [14] provides more details on fretting fatigue. Although many researchers have experimentally studied fretting fatigue in the literature [15, 16], very few have used numerical models [17]. This is due to the fact that modeling of fretting fatigue is complicated and requires the application of several theories including contact mechanics, stress analysis, damage mechanics and fracture mechanics. Shkarayev and Mall [18] have constructed a finite element model and studied the fretting fatigue crack propagation. They reported that the maximum tangential stress drives the direction of crack growth. After an initial kinking, the fretting fatigue crack propagated in a direction almost normal to the contact surface. Fadag et al. [17] have used FE sub-modelling technique for predicting crack initiation and crack propagation life time.

\section{DAMAGE MECHANICS}

In order to determine fatigue damage parameters, bulk adhesive specimens were experimentally tested under fatigue loading [2]. The bulk adhesive specimens were made from epoxy resins, FM-73 film adhesives supplied by Cytec ${ }^{\mathrm{TM}}$. Two types of experiments have been performed; namely tensile tests and fatigue tests. To obtain the equivalent stress as a function of number of cycles, low cycle fatigue (LCF)-strain based test of bulk adhesive was performed. The minimum displacement was 0.24 $\mathrm{mm}$, maximum displacement was $1.4 \mathrm{~mm}$ and test frequency was $5 \mathrm{~Hz}$. Tensile tests were performed in order to obtain mechanical properties, which were needed for damage evolution formula and finite element analysis. Stress-strain curve was fitted to Ramberg-Osgood formula [19]. From curve fitting process, the material properties 
of the bulk adhesive were obtained as; $E=1160 \mathrm{~N} / \mathrm{mm}^{2}, K=61.437 \mathrm{~N} / \mathrm{mm}^{2}$ and $m=$ 0.08 , where $E$ is Young's modulus and $K$ and $m$ are Ramberg-Osgood parameters. During strain-based controlled test, stress degradation takes place. Using the damage equation based on thermodynamics principles developed by Abdel Wahab et. al. [20], the damage variable $(D)$ as a function of number of cycles, applied stress range and triaxiality function is obtained as:

$$
D=1-\left[1-A(\beta+m+1)\left(\Delta \sigma_{e q}\right)^{\beta+m} R_{V}^{\beta / 2} N\right]^{\frac{1}{\beta+m+1}}
$$

where $D$ is the damage variable, $N$ is the number of cycles, $\Delta \sigma_{e q}$ the range of von Mises stress, $R_{V}$ the triaxiality function, $m$ the power constant in Ramberg-Osgood equation, and $A$ and $\beta$ are damage parameters to be determined experimentally. From the strain-based controlled test, Damage variable $D$, can be determined as [2]:

$$
D=1-\frac{\Delta \sigma_{e q}}{\Delta \sigma_{e q} *}
$$

where $\Delta \sigma_{e q}^{*}$ is von Mises stress range for virgin material (undamaged state) or at stabilization of harding. By curve fitting Equation (1) to the experimental results, determined by Equation (2), the damage parameters $A$ and $\beta$ can be calculated for each applied load level. Figure 1 shows a comparison between the damage variable determined from experiments and predicted (fitted) damage curves (plotted using Equation (1)).

In order to determine the damage parameters for different triaxiality functions, a single lap joint has been analysed for fatigue crack initiation [21]. Two dimensional plain strain element, Plane82 (ANSYS element library), has been used to model both substrates and adhesive layer. This is a higher order element, has mid-side nodes in the element edges, produces more accurate results and tolerates irregular shapes without much loss of accuracy. The single lap joint specimen dimensions and boundary conditions are similar to those used in the fatigue experiments performed by Solana [22]. In single lap joints, stress singularities take place at the corners as illustrated in Fig. 2(a). In order to obtain accurate results near singularity corners, very fine mesh near these points is necessary as shown in Fig. 2(b). Because the element size near singularity tips will contribute directly to the computational time, it is important to compromise between accuracy and CPU time. An example of von Mises stress contour plot is shown in Fig.3.

In order to apply the damage evolution law to a single lap joint, the triaxiality function is required and, therefore, two types of stress should be determined from FEA; namely von Mises equivalent stress and Hydrostatic Stress. The triaxiality function can be written as [20] $R_{v}=\frac{2}{3}(1+v)+3(1-2 v) T_{x}^{2}$, where $v$ is Poisson's Ratio and $T_{x}$ is the triaxiality ratio defined as the ratio between the hydrostatic stress $\sigma_{H}$ and von Mises equivalent stress $\sigma_{e q}$. Since the hydrostatic stress and von Mises equivalent stress are available in ANSYS, contour plot of triaxiality function, $R_{v}$ can be 
calculated. At failure, when the number of cycles to failure, $N_{f}$, is reached, $D$ becomes 1 (fully damaged state) so that fatigue lifetime can be predicted as [20]:

$$
N_{f}=\frac{\Delta \sigma_{e q}^{-\beta-m} R_{v}^{-\frac{\beta}{2}}}{A(\beta+m+1)}
$$

By curve fitting of Equation (3) to experimental results, the damage parameters $A$ and $\beta$ can be determined as function of applied load range or applied stress $\Delta \sigma_{e q}$. When comparing $A$ and $\beta$ obtained from single lap joint analysis to those obtained from bulk adhesive [2], it could be concluded that the damage parameters do not only depend on $\Delta \sigma_{e q}$ but also on the trixiality function $R_{v}$. It could also be demonstrated that the multi-axial stress state in the single lap joint leads to different triaxiality functions distributed along the adhesive layer [21].

In order to characterise the triaxialty and design an experimental specimen, several types of joint have been examined using FEA [23]. A butt joint under only tension, only torsion or a combination of tension and torsion loading is modelled. Based on the standard geometry of ASTM STP, three-dimensional model was developed in ANSYS workbench (ANSYS, Inc., Berkeley, USA). Figure 4(a) shows the distribution of von Mises stress in case of torsion loading. Using the function "Meshgrid" in Matlab, the triaxiality function $\left(R_{v}\right)$ could be plotted as a surface function. En example for the case of torsion load is shown in Fig. 4(b). The result shows a flat surface with a constant triaxiality function of 0.92 and a peak at the centre of the butt joint. It was concluded that the triaxiality function lies between two extreme values, i.e. 0.92 (pure shear stress state) and 3.5 (multi-axial stress state). Therefore, in order to control the triaxiality function in butt joints, a mixed loading condition between tension and torsion should be applied. From further analysis, it was also concluded that the triaxiality could not be simply controlled (i.e. constant value in the adhesive layer) by adjusting the ratio between tension and torsion loads.

The second type of joint that has been examined is cleavage joint, which shows mixed stresses even if it is only subjected to tension load [23]. Finite element analysis was performed to a cleavage joint under tension load of $1000 \mathrm{~N}$. FE mesh of a cleavage joint is illustrated in Fig. 5(a). An example of a plot of triaxiality function for cleavage joint for bondline angle $\theta=18.5^{\circ}$ is shown in Fig.5(b). It was found that the range of triaxiality functions produced by a cleavage joint was between a minimum of 0.92 and a maximum of 3.5. It was also concluded that the triaxiality profiles along the bondline depend on the bondline angle, but the triaxiality function is not constant along the bondline length for a given bondline angle.

A third type of joint that has been examined for triaxiality distribution in the adhesive layer is scarf joint, which has simpler profile compared to cleavage joint. Opposite to cleavage joint, the load applied to a scarf joint is tension and co-linear (i.e. no load eccentricity), and thus no bending moment effect is expected. However, because in scarf joint a bondline angle exists, the applied load is transferred into tensile and shear stresses. The 3-D FE mesh of a scarf joint is shown in Fig. 6(a). Triaxiality function was calculated and plotted along the length and width of adhesive layer as shown in Fig. 6(b). Apart from the edges, the triaxiality function has a constant value 
of 1.67. Near the edges, triaxiality drops and a ripple effect takes place. After considering five different bondline angles, it was concluded that for every bondline angle, the triaxiality function has a constant value along its bondline region away from edges, where stress singularity has no effect. Therefore, scarf joint was found to be the most suitable joint type to control triaxiality in the adhesive layer.

\section{FRACTURE MECHANICS}

Fatigue crack growth analysis and lifetime prediction require the development of a crack growth equation that relates crack growth rate to fracture parameters such as stress intensity factor or strain energy release rate. An example of a crack growth equation is the modified Paris law that relates the crack growth rate $(d a / d N)$ to the maximum strain energy release rate $\left(G_{\max }\right)$, at a specific stress ratio, is given by [24]:

$$
\frac{d a}{d N}=A G_{\max }^{n}\left[\frac{1-\left(\frac{G_{t h}}{G_{\max }}\right)^{n_{1}}}{1-\left(\frac{G_{\max }}{G_{c}}\right)^{n_{2}}}\right]
$$

where $G_{t h}$ is the fatigue threshold and $G_{c}$ is the fracture toughness. The constants $n$, $n_{1}$ and $n_{2}$ can be determined by fitting Equation (4) to experimental data. The number of cycles to failure can be obtained by integrating Equation (4) from an initial crack length $\left(a_{o}\right)$ to a final crack length $\left(a_{f}\right)$, i.e.

$$
N_{f}=\int_{a_{o}}^{a_{f}} \frac{1}{d a / d N} d a=\int_{a_{o}}^{a_{f}} \frac{\left(1-\left(\frac{G_{\max }}{G_{c}}\right)^{n_{2}}\right)}{A G_{\max }^{n}\left(1-\left(\frac{G_{t h}}{G_{\max }}\right)^{n_{1}}\right)} d a
$$

Equation (5) can be numerically integrated using FEA to determine the required fracture parameters $\left(G_{\max }\right.$ as a function of crack length a) [24]. A further modified form of the crack growth law that takes into account contributions from mode I and mode II components is proposed as [24]:

$$
\frac{d a}{d N}=A_{I} G_{I}^{n_{I}}\left[\frac{1-\left(\frac{G_{I_{I h}}}{G_{I}}\right)^{n_{1 I}}}{1-\left(\frac{G_{I}}{G_{I c}}\right)^{n_{2 I}}}\right]+A_{I I} G_{I I}^{n_{I I}}\left[\frac{1-\left(\frac{G_{I I I t}}{G_{I I}}\right)^{n_{I I I}}}{1-\left(\frac{G_{I I}}{G_{I I c}}\right)^{n_{2 I I}}}\right]
$$

where the subscripts I and II refer to mode I and mode II, respectively. However, in order to use Equation (6) pure mode II and mixed mode fatigue tests are required. For this purpose, a mixed mode loading jig for testing of Double Cantilever Beam (DCB) adhesively bonded specimens is designed as illustrated in Fig. 7(a) [25]. This 
loading jig has the capability to cover a wide range of mode mixities from pure mode I to pure mode II. The jig consists of a link arm system that allows the control of the ratio of the forces applied at both upper and lower sides of the DCB specimen. FE model and deformation of DCB test specimen mounted on the jig is shown in Fig. 7(b). A 2-D linear elastic FE model of the DCB specimen was constructed to determine the fracture parameters $G_{\|}$and $G_{\|}$. Plane strain 8-noded quadrilateral elements were used to model both substrates and adhesive layer. FE mesh is shown in Fig. 8(a), while mixed mode deformation near the crack tip is illustrated in Fig. 8 (b). The strain energy release rate components, $G_{\|}$and $G_{\|}$, were calculated using the Virtual Crack Closure Technique (VCCT) [26], which is applicable for linear elastic case. An interfacial crack was introduced between lower substrate and adhesive layer, which is usually observed for a very thin adhesive layer.

\section{FRETTING FATIGUE}

When two contacting components are simultaneously subjected to oscillating loads and sliding movements, fretting fatigue damage may take place. Fretting fatigue may cause catastrophic failure and significant reduction in lifetime of structural components. A fretting fatigue test specimen is illustrated in Fig.9(a). In the current FE model, the specimen is made of Aluminium alloy 7075-T6. This alloy is widely used in industrial applications such as aircraft structures and pressure vessels. Details of mechanical properties and dimensions can be found in reference [27]. The FE mesh, which was generated in the FE package ABAQUS (version 6.10), is shown in Fig. 9(b) [28]. Four-noded plane stress elements (CPS4R) were used to model both specimen and pad. The contact between pad and specimen was modeled using the master-slave interfacial algorithm available in ABAQUS. This algorithm makes use of Lagrange multiplier with a coefficient of friction of 0.5 . The function of the contact algorithm is to allow load transfer between the contact pad and the specimen without penetration. Only one quarter of the specimen is modeled taking advantage of symmetry. Symmetric boundary conditions along the lines of symmetry were applied and the specimen is analyzed under the action of the load $F$ and pressure $\sigma_{\text {axial. }}$. The contact load, $\mathrm{F}$, was firstly applied to establish contact between pad and specimen, and then followed by either the maximum bulk stress, $\sigma_{\max }$, or the minimum bulk stress, $\sigma_{\min }$.

In order to perform fretting fatigue crack propagation analysis, the fracture mechanics FE code, FRANC2D/L [29] was used. FRANC2D/L code has the capability to simulate incremental crack growth using fracture mechanics principles. A finite element model similar to the one described above having the same geometry and boundary conditions were constructed. A starter edge crack was inserted in the model at the expected location of crack initiation. Mesh refinement was carried out in order to validate the calculated stresses in the FRANC2D/L code. A comparison between FRANC2D/L results and those obtained from another FE model was performed. A difference of less than $1 \%$ was observed between the two sets of results. The contact was modelled using a gap element with coefficient of friction equal to 0.5 . The stress intensity factors were calculated after each crack increment taking into account the effect of contact stresses between specimen and pad. Curvilinear straight segments, S-shape, were used to represent the crack propagation path as shown in Fig. 10(a). An initial crack of $0.01 \mathrm{~mm}$ length and with 
an orientation of $45^{\circ}$ was introduced at the sharp edge of the contact surface. This position is obtained based on stress analysis of un-cracked specimen and from experimental results observations. As illustrated in Fig.10(a), the analysis was performed with a crack length increment of $\Delta l$. In the first crack increment, the incremented crack with coordinates $\left(\mathrm{x}_{2}, \mathrm{y}_{2}\right)$ kinked at the tip from the initial crack with coordinates $\left(\mathrm{x}_{1}, \mathrm{y}_{1}\right)$ and a new crack surface was created at a slope of $\theta_{2}$. This process was continued until the final crack length was reached. The maximum tangential stress was used to determine the crack growth direction and the crack angle, $\theta_{i}$ at the $i^{\text {th }}$ step calculated as [30]:

$\theta_{i}=\theta_{i-1}+2 \tan ^{-1}\left[\frac{\left.K_{I \operatorname{maxi}}-\sqrt{K_{\operatorname{maxi}}^{2}+8 K_{I I m a x i}^{2}}\right]}{4 K_{1 I \operatorname{maxi}}}\right]$

where $K_{\text {Imaxi }}$ and $K_{\text {IImaxi }}$ are the stress intensity factors at the ith step for modes I and II at the maximum load. The crack trajectory was then incrementally determined for a given loading condition. Furthermore, the crack growth rate was governed by the maximum and minimum Mode I stress intensity factors, $K_{\text {Imax }}$ and $K_{\text {Imin }}$, which are extracted from FEA using the modified crack closure integral technique [26]. The crack propagation lifetime was determined using a sigmoidal crack growth model measured from fatigue experiments [31]. Final failure took place when the stress intensity factor, $K_{l}$ reached its critical value, $K_{/ C}$. FRANC2D/L CRACK GROWTH code extracts the stress intensity factor as a function of crack length and integrates the crack growth rate da/dN (NASGRO model) for a given applied load. It uses the Forman NASGRO material model, which is given by [32]:

$\frac{d a}{d N}=C\left[\left(\frac{1-f}{1-R}\right) \Delta K\right]^{n} \frac{\left(1-\frac{\Delta K_{t h}}{\Delta K}\right)^{p}}{\left(1-\frac{K_{\max }}{K_{\text {crit }}}\right)^{q}}$

where $C, n, p$ and $q$ are empirical constants, which are obtained by curve fitting the fatigue experimental data and $f$ is the ratio between mode I stress intensity factor and the maximum stress intensity factor. The threshold stress intensity range $\Delta K_{\text {th }}$ includes the effect of short crack by involving an intrinsic crack length and the parameter $f$. The empirical constants were $C=6 \times 10^{-10}$ and $n=2.51$. An example for a crack propagation analysis using FRANC2D/L CRACK GROWTH code is shown in Fig. 10(b).

\section{CONCLUSIONS}

In this paper, recent research work on Finite Element Analysis and its application to model and predict the behaviour of structures under damage, fracture, fatigue and fretting fatigue conditions are reviewed. The use of FEA in three different problems is presented. Firstly, FE code is combined with a continuum damage model to predict the number of cycles to crack initiation in adhesively bonded joints. Secondly, FE code is integrated with a crack propagation algorithm using the principles of fracture mechanics and Paris law to predict the crack growth lifetime of DCB specimens. Finally, FE code is combined with contact mechanics and fracture mechanics to 
model fretting fatigue of an aluminium test specimen and predicts its crack propagation fatigue lifetime.

\section{ACKNOWLEDGEMENTS}

The authors wish to thank the Gent University (Belgium) for the financial support (BOF 01N02410).

\section{REFERENCES}

[1] Timoshenko, S.P., History of Strength of Materials, Donner Publication, (1982).

[2] Abdel Wahab, M.M., Hilmy, I., Ashcroft, I.A. and Crocombe, A,D., "Evaluation of fatigue damage in adhesive bonding: Part 1 bulk adhesive", J. of Adhesion. Sci. and Tech., Vol. 24, pp. 305-324, (2010).

[3] Crocombe, A.D., Ong, C.Y., Chan, C.M., Abdel Wahab, M.M. and Ashcroft, I.A., "Investigating fatigue damage evolution in adhesively bonded structures using backface strain measurement", J. of Adhesion, Vol. 78, No. 9, pp. 745778, (2002).

[4] Harris, J.A. and Fay, P.A., Int. J. of Adhesion and Adhesive, Vol. 12, pp.9, (1992).

[5] Marcadon, V., Nadot, Y., Roy, A. and Gacougnolle, J.L., Int. J. of Adhesion and Adhesives, 26, 481 (2006).

[6] Zhang, Z., Shang J.K. and Lawrence, F.V., J. of Adhesion, Vol. 49, pp. 23, (1995).

[7] Fernlund, G., Spelt, J.K., "Failure load prediction of structural adhesive joints: Part 2: Experimental study", Int. J. Adhesion and Adhesive, Vol. 11, pp. 221227, (1991).

[8] Fernlund, G., Spelt, J.K., "Mixed-mode fracture characterization of adhesive joints", Comp. Sci. Tech., Vol. 50, pp. 441-449, (1994).

[9] Johnson, W.S., "Stress analysis of the cracked-lap-shear specimen: an ASTM round-robin", J. Test Eval., Vol. 6, pp. 303-324, (1987).

[10] Hashemi, S., Kinloch, K.J. and Williams J.G., "Mixed-mode fracture in fiberpolymer composite laminates. In: Delamination and debonding of materials, ASTM STP 1110”, T.K.O`Brien Ed., Amer. Soc. for Tes. and Mat., pp. 143162, (1991).

[11] Buch, A., "Fatigue and fretting of pin-lug joints with and without interference fit", Wear, pp. 43:9, (1977).

[12] Hattori, T., Kawai, S., Okamoto N., and Sonobe, T., "Torsional fatigue strength of a shrink-fitted shaft", Bull JSME, Vol. 24, No. 197, pp. 1893, (1981).

[13] Johnson, R.L. and Bill, R.C., "Fretting in aircraft turbine engines", NASA TM X-71606, (1974).

[14] Hills, D.A. and Novell, D., "Mechanics of Fretting Fatigue", Kluwer Academic, Publishers, Dordrecht, (1994).

[15] Nicholas, T., Huston, A., John, R. and Olson, S., "A fracture mechanics methodology assessment for fretting fatigue", International Journal of Fatigue, Vol. 25, pp. 1069-1077, (2003). 
[16] Golden, P. and Shepard, M., "Life prediction of fretting fatigue with advanced surface treatments", Mat. Sci. and Eng. A, Vol. 468-470, 15-22, (2007).

[17] Fadag, H.A., Mall, S. and Jain, V.K., "A finite element analysis of fretting fatigue crack growth behavior in Ti-6Al-4V", Engineering Fracture Mechanics, Vol. 75, No. 6, pp. 1384-1399, (2008).

[18] Shkarayev, S. and Mall, S., "Computational modelling of shot-peening effects on crack propagation under fretting fatigue", J. Strain Anal. Eng, Vol. 38, No. 6, pp. 495-506, (2003).

[19] Ramberg, W. and Osgood, W.R., "Description of Stress-Strain Curves by Three Parameters", Technical Note No. 902, National Advisory Committee For Aeronautics, Washington DC, (1943).

[20] Abdel Wahab, M.M., Ashcroft, I.A., Crocombe, A.D. and Shaw, S.J., "Prediction of fatigue thresholds in adhesively bonded joints using damage mechanics and fracture mechanics", Journal of Adhesion Science Technology, Vol. 15, No. 7, pp. 763-782 (2001).

[21] Abdel Wahab, M. M., Hilmy, I., Ashcroft, I. A. and Crocombe, A. D., "Evaluation of fatigue damage in adhesive bonding: Part 2 single lap joint", Journal of Adhesion Science and Technology, Vol. 24, pp. 325-345 (2010).

[22] Solana, A.G., "Fatigue Initiation In Adhesively Bonded Joints", PhD Thesis, University of Surrey, (2008).

[23] Abdel Wahab, M. M., Hilmy, I., Ashcroft, I. A. and Crocombe, A. D., "Damage parameters of adhesive joints with general triaxiality: Part 1 finite element analysis", Journal of Adhesion Science and Technology, Vol. 25, pp. 903-923, (2011).

[24] Abdel Wahab, M. M. , Ashcroft, I. A., Crocombe, A. D. and Smith, P.A., "Numerical prediction of fatigue crack propagation lifetime in adhesively bonded structures", International Journal of Fatigue, Vol. 24, No. 6, pp. 705709, (2002).

[25] Hafiz, T.A., Abdel Wahab, M.M., Smith, P.A. and Crocombe, A.D., "Mixedmode fracture of adhesively bonded metallic joints under quasi-static loading", Engineering Fracture mechanics, Vol. 77, No. 17, pp. 3434-3445, (2010).

[26] Abdel Wahab, M.M., "On the use of fracture mechanics in designing a single lap adhesive joint", J Adhes Sci Tech, Vol. 14, pp.851-865, (2000).

[27] Hojjati Talemi, R. and Abdel Wahab, M.M., "Numerical investigation into effect of contact geometry on fretting fatigue crack propagation lifetime", Tribology, In press, (2012).

[28] Abdel Wahab, M.M., Hojjati Talemi, R. and De Baets, P., "FEA of fretting fatigue: A comparison between ANSYS and ABAQUS", Key Engineering Materials, Vols. 488-489, pp. 662-665, (2012).

[29] FRANC2D/L, A crack propagation simulator for plane layered structures, Ithaca, New York: Cornell University, (1998).

[30] Hojjati Talemi, R., Abdel Wahab, M.M. and De Baets, P., "Numerical modeling of fretting fatigue", $9^{\text {th }}$ International Conference on Damage Assessment of Structures, DAMAS, Oxford, UK, 11-13 July (2011).

[31] Shkarayev S., Mall, S., J. Str. Anal. Eng. Des, Vol. 38, pp. 495-506, (2003).

[32] Forman R.G., Mettu S.R., Frac. Mech. 22nd Symp., Vol. 1 (Philadelphia: ASTM), (1992). 


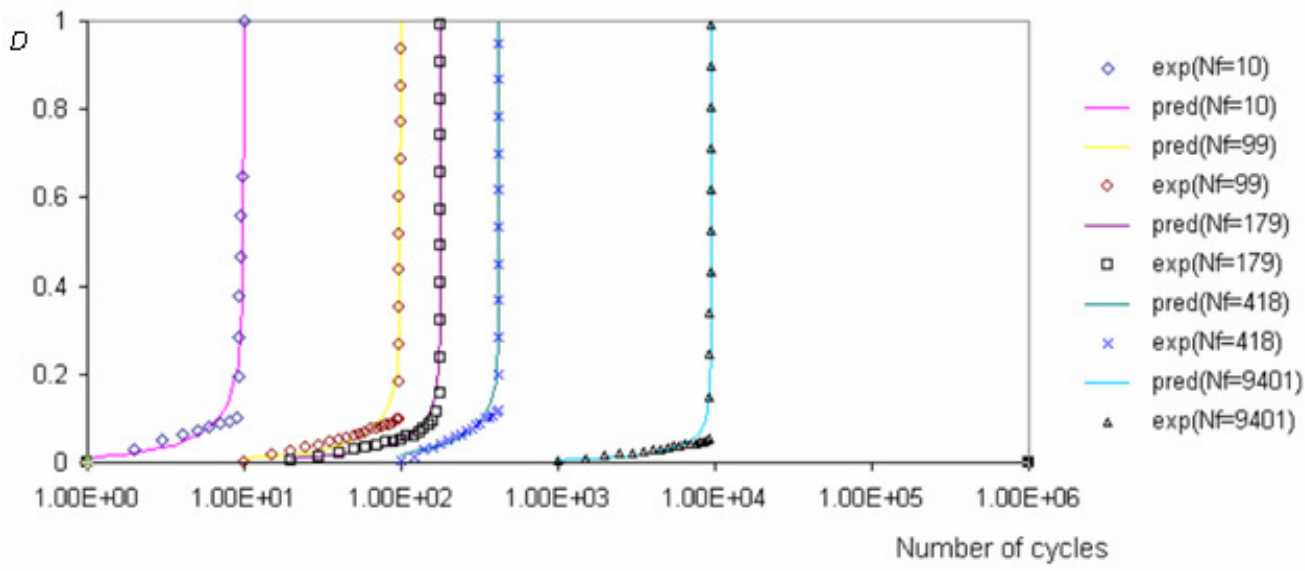

Fig.1. Comparison between experimental and predicted damage variable ' $D$ ' [2]

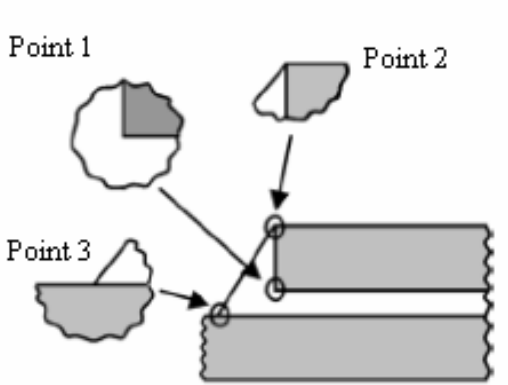

(a)

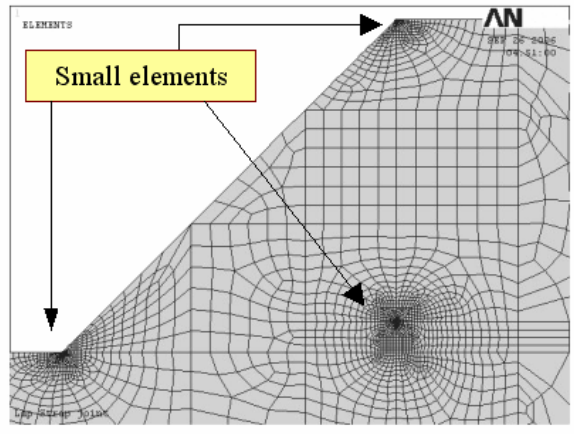

(b)

Fig.2. (a) Points of stress singularity in a single lap joint and (b) FE mesh [21]
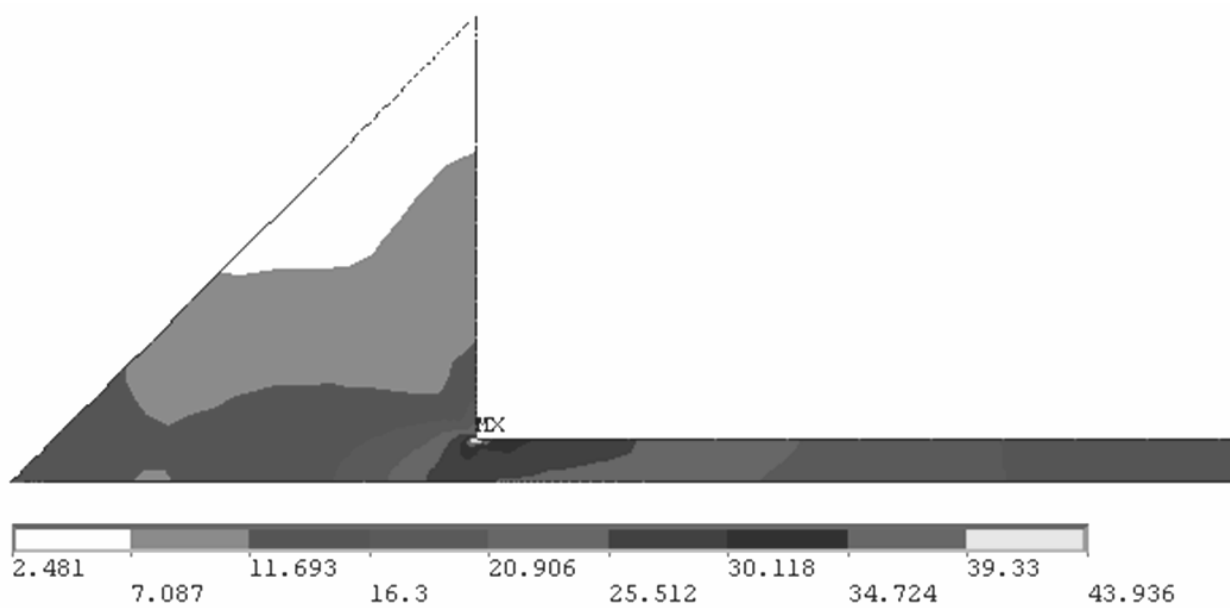

Fig.3. Contour of von Mises stress (MPa) in adhesive layer at load level $30 \%$ of static failure load [21]. 


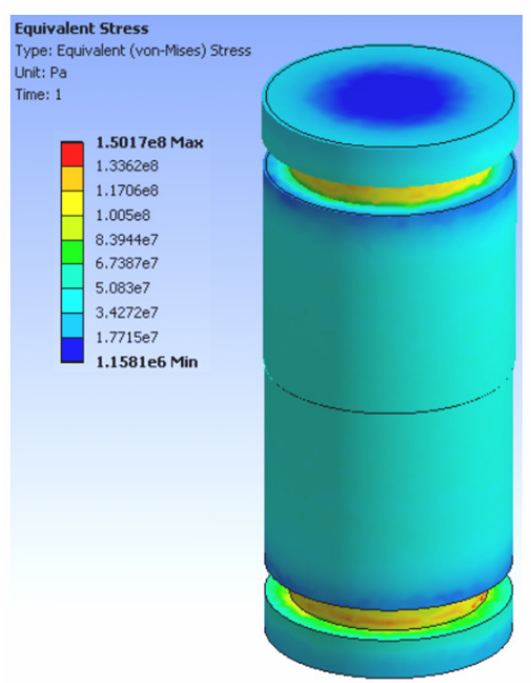

(a)

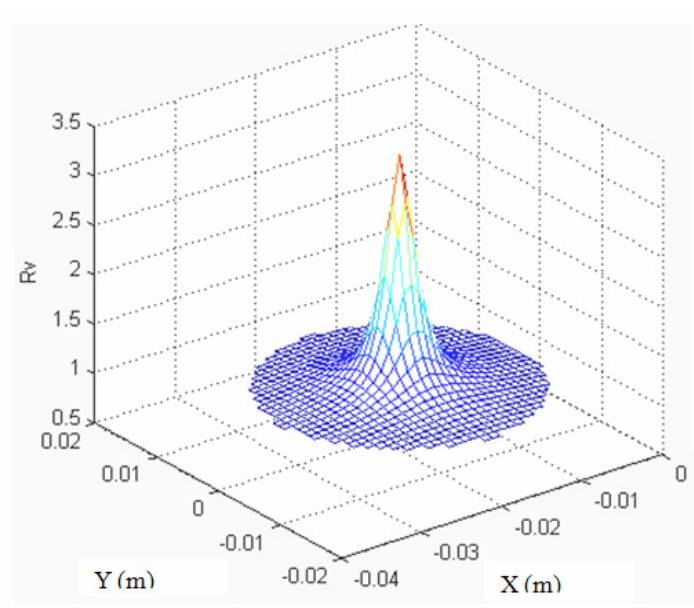

(b)

Fig.4. FEA of butt joint (a) von Mises stress (MPa) under torsion load and (b) triaxiality function under mixed load in adhesive layer [23]

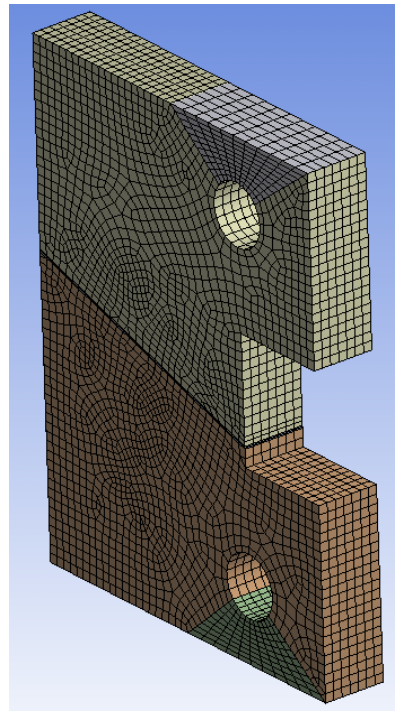

(a)

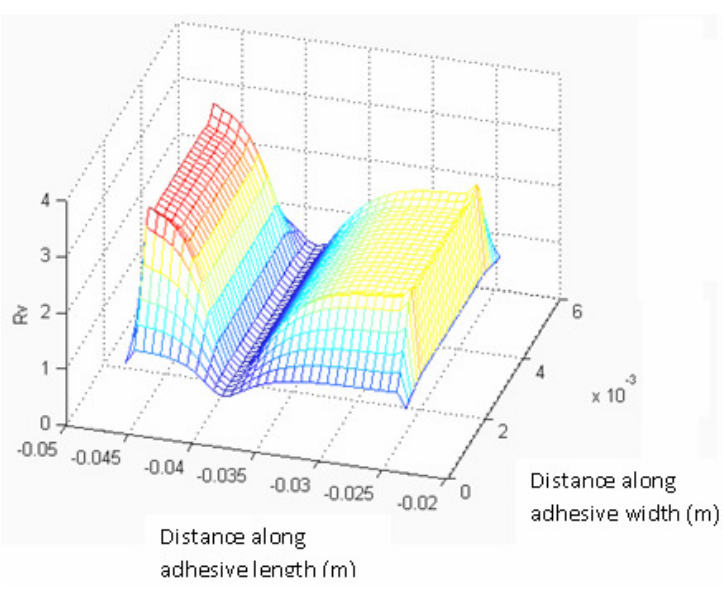

(b)

Fig.5. Cleavage joint under tension load (a) FE mesh and (b) triaxiality function in adhesive layer [23] 


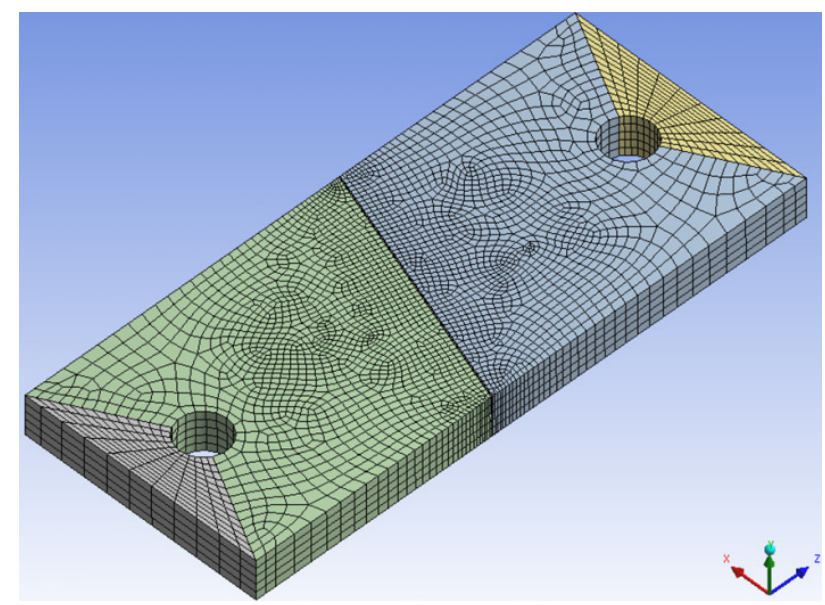

(a)

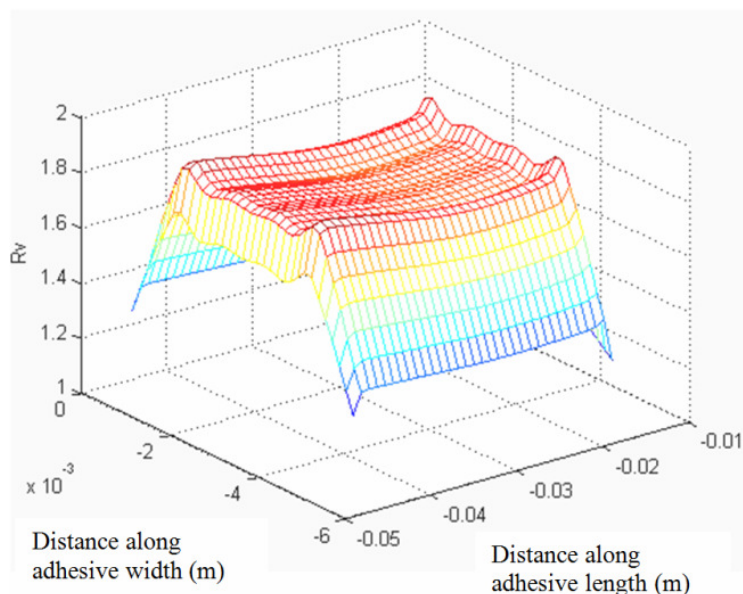

(b)

Fig.6. Scarf joint under tension load (a) FE mesh and (b) triaxiality function in adhesive layer [23]

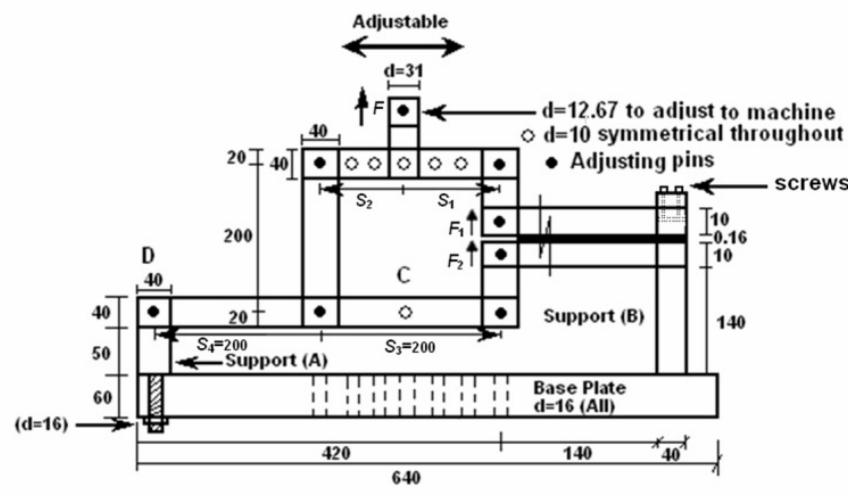

(a)

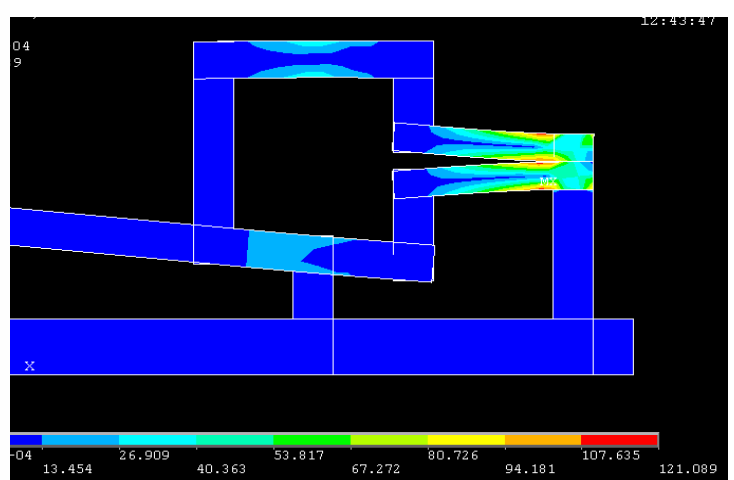

(b)

Fig.7. Mixed mode loading jig (a) dimensions (mm) and (b) FE model [25]

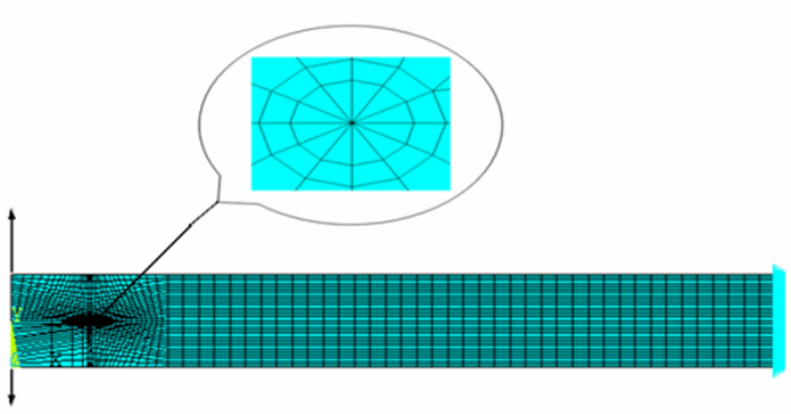

(a)

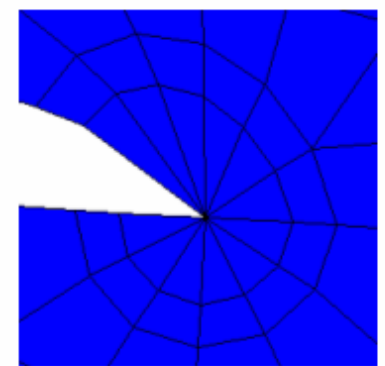

(b)

Fig.8. DCB test specimen (a) FE mesh and (b) deformation near crack tip [25] 

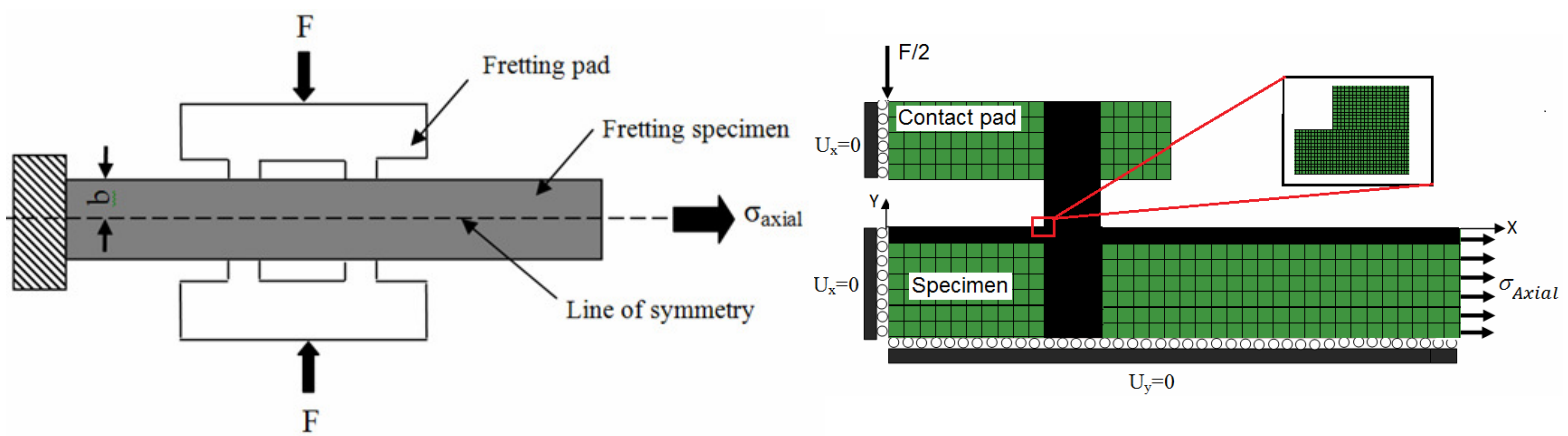

Fig.9. Fretting fatigue test specimen (a) Geometry [27] and (b) FE mesh [28]

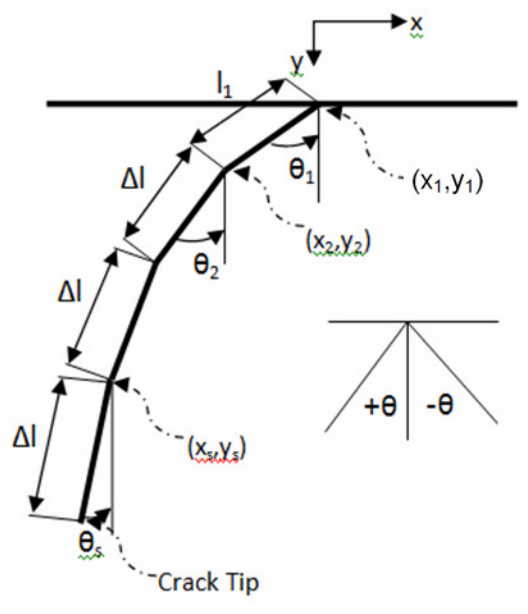

(a)

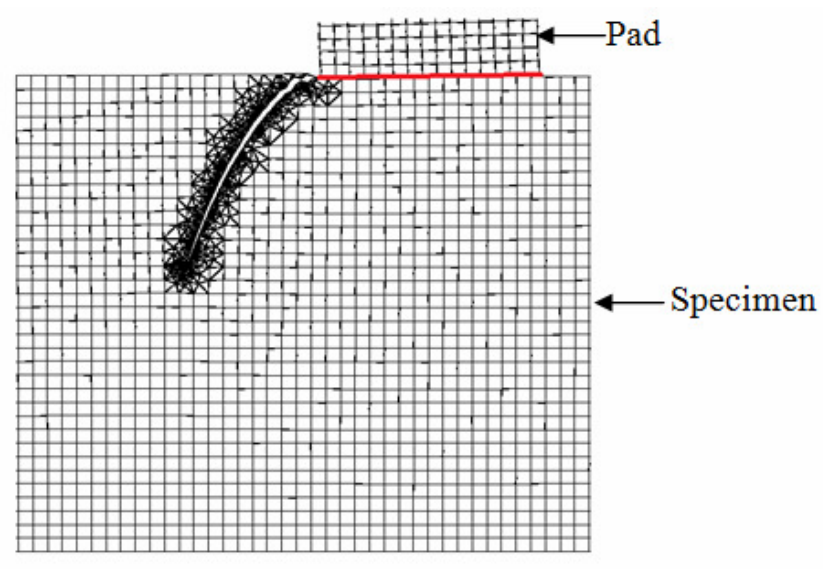

(b)

Fig.10. Fretting fatigue crack propagation (a) crack path and (b) FE mesh [30] 